\title{
Administration of Neutralizing Antibodies to Interleukin-6 (IL-6) Reduces Experimental Autoimmune Encephalomyelitis and Is Associated with Elevated Levels of IL-6 Bioactivity in Central Nervous System and Circulation
}

\author{
Koenraad Gijbels,* Stefan Brocke,* John S. Abrams, ${ }^{\dagger}$ \\ and Lawrence Steinman* \\ *Department of Neurology and Neurological Sciences, Stanford \\ University School of Medicine, Stanford, California, U.S.A. \\ ${ }^{\dagger}$ Department of Molecular Biology, DNAX Research Institute, \\ Palo Alto, California, U.S.A.
}

\begin{abstract}
Background: We previously demonstrated the local production of the pleiotropic cytokine interleukin-6 (IL-6) in the central nervous system (CNS) in experimental autoimmune encephalomyelitis (EAE), an animal model for the human disease multiple sclerosis.

Materials and Methods: To assess the role of IL-6 in autoimmune CNS inflammation, we administered neutralizing antibodies to IL- 6 in the EAE model. Their effect was examined at the clinical and histopathological level. Levels of administered antibody and IL- 6 bioactivity were followed in serum and cerebrospinal fluid (CSF). Results: Systemically administered antibodies penetrated into the fluid CSF in animals in which EAE was induced. Administration of anti-IL-6 reduced the development of actively induced as well as adoptively trans-
\end{abstract}

ferred EAE and was associated with increased levels of IL-6 activity in the CSF and to a lesser extent in the serum. Anti-IL-6 was still effective when given 1 day before the onset of disease signs in adoptively transferred EAE. The disease-reducing effect of anti-IL- 6 was also reflected at the pathological level by the absence of inflammatory infiltrates in the CNS.

Conclusions: Our study indicates that IL-6 plays an important role in autoimmune CNS inflammation. However, due to the complex nature of the in vivo interactions of administered antibodies, the disease-reducing effect of the anti-IL- 6 antibodies could be caused by neutralization of IL- 6 activity or by enhancement of IL- 6 activity via induction of higher IL-6 levels in the CNS.

\section{INTRODUCTION}

Interleukin-6 (IL-6) is a pleiotropic cytokine which is present during inflammation (1). Elevated IL-6 levels are found in vivo in almost every infectious and/or inflammatory condition. IL-6 is detectable in the cerebrospinal fluid (CSF)

Address correspondence and reprint requests to: Koenraad Gijbels, Department of Neurology and Neurological Sciences, Beckman Center, Room B002, Stanford University Medical Center, Stanford, CA 94305-5429, U.S.A. during viral, bacterial, and fungal infections of the central nervous system (CNS) in humans, and in experimental viral infection of the CNS in animals (2-5). Elevated levels of IL-6 are also detectable in various diseases in which autoimmunity may play a role, such as rheumatoid arthritis (6) and lupus erythematosus (7). But, little if any IL- 6 has been detected in the CSF of multiple sclerosis (MS) patients $(2,3,8,9)$, although MS is also considered to be of autoim- 
mune origin. Surprisingly, two groups found that IL-6 levels in the circulation of MS patients were frequently elevated and were higher than levels in CSF $(5,10)$. In diseases in which inflammation is mainly limited to a well-defined compartment of the body (e.g., joint or meningeal space), IL-6 levels are typically much higher locally than in the serum, suggesting local production of the cytokine and subsequent release into the bloodstream. We previously reported IL-6 production in the CNS of animals that were developing experimental autoimmune encephalomyelitis (EAE), an animal model for autoimmune inflammation of the CNS (11). Elevated IL-6 levels in EAE are associated with disease onset, as in other inflammatory CNS disorders (12). Possible explanations for the discordance between the findings in MS and EAE could be that IL- 6 is only produced in MS when the disease is initiated or during periods of lesion formation, making sampling time critical. In addition, IL- 6 produced locally in the lesions may not reach the CSF. The detection of IL-6 immunoreactivity in microglial cells and in reactive astrocytes in active MS plaques supports the latter hypothesis (13).

IL-6 is an important mediator in various immunological and inflammatory processes that play a role in the pathogenesis of CNS disorders such as MS (e.g., stimulation of T cell-mediated immunity and local antibody production). IL-6 has both pro- and anti-inflammatory effects (14). The net in vivo effect and role of IL-6 are difficult to predict because of its pleiotropic nature. In the present study we used neutralizing mAb to IL-6 to examine the role of IL- 6 in the pathogenesis of EAE and to evaluate the potential use of antiIL-6 therapy in inflammatory CNS disorders.

\section{MATERIALS AND METHODS}

\section{Actively Induced EAE}

EAE was induced in female SJL mice 7-10 weeks old (Jackson Laboratories, Bar Harbor, MI) by s.c. injection of $100 \mu \mathrm{l}$ of an emulsion consisting of $5 \mathrm{mg}$ lyophilized SJL mouse spinal cord homogenate (MSCH) plus $0.2 \mathrm{mg}$ Mycobacterium tuberculosis (strain H37RA) in phosphate-buffered saline (PBS)/(v/v) (Difco, Detroit, MI, U.S.A.). On the same day and $48 \mathrm{hr}$ later, the mice also received $0.4 \mu \mathrm{g}$ of Bordetella pertussis toxin (List Biological Laboratories, Campbell, CA, U.S.A.) in $100 \mu \mathrm{l}$ PBS i.v. The mice were scored daily according to the following clinical scale: no neuro- logical signs $=$ grade 0 , weak tail $=$ grade 1 , wobbly walk or limb paresis $=$ grade $2, \operatorname{limb}$ paralysis $=$ grade 3 , inability to move $=$ grade 4 , death $=$ grade 5 . Easy access to food and water was provided, and animals with grade 3 or 4 received daily parenteral fluid. Scoring was performed by an observer unaware of the treatment.

\section{Adoptively Transferred EAE}

Female PLSJLF1 mice (Jackson Laboratories) were used at age 6-10 weeks. Mice were subcutaneously injected with $200 \mu \mathrm{g}$ of the MBP peptide Acl-11 (according to the sequence AcASQKRPSQRHG) (Protein and Nucleic Acid Facility, Stanford, CA, U.S.A.) in an emulsion of (PBS) and complete Freund's adjuvant (CFA) $(\mathrm{v} / \mathrm{v})$. After 8-10 days the draining lymph nodes were removed and processed through a steel mesh until a single-cell suspension was obtained. The resulting cells were cultured at a concentration of $6 \times 10^{6}$ cells $/ \mathrm{ml}$ in RPMI-1640 medium supplemented with $10 \%$ heat-inactivated fetal calf serum (Hyclone, Logan, UT, U.S.A.), $2 \mathrm{mM}$ glutamine, $100 \mathrm{U} / \mathrm{ml}$ penicillin and $100 \mu \mathrm{g} / \mathrm{ml}$ streptomycin, $5 \times 10^{-5} \mathrm{M} \beta$-mercaptoethanol (=supplemented medium; all reagents from Gibco, Grand Island, NY, U.S.A.) and $10 \mu \mathrm{g} / \mathrm{ml}$ MBP peptide Acl-1 1 at $37^{\circ} \mathrm{C}$ and $6 \% \mathrm{CO}_{2}$. After 4 days of incubation the cells were washed and cultured at a concentration of $6 \times 10^{6}$ cells $/ \mathrm{ml}$ for 10 days in supplemented medium, without antigen. The resulting $\mathrm{T}$ cell line was maintained by restimulating the cells $\left(6 \times 10^{6}\right.$ cells $\left./ \mathrm{ml}\right) \mathrm{ev}$ ery 14 days with MBP peptide Acl-11 $10 \mu \mathrm{g} / \mathrm{ml}$, presented by irradiated (3000 rad) syngeneic splenocytes $\left(6-10 \times 10^{6}\right.$ cells $\left./ \mathrm{ml}\right)$ for 4 days. For transfer, cells were harvested 3 days after stimulation, extensively washed in PBS and 3.5-5 $\times$ $10^{6}$ cells/mouse were injected i.v. Scoring was performed as for actively induced EAE.

\section{Sampling}

Mice were sacrificed by $\mathrm{CO}_{2}$ inhalation. Blood was taken via cardiac puncture, whereafter it was allowed to clot and serum was separated by centrifugation. After incision of the skin over the neck and dissection of the underlying muscles, CSF was taken by puncture of the meninges between the occiput and first vertebra, avoiding the blood vessels (2-5 $\mu \mathrm{l} /$ mouse) (15). Samples visibly contaminated with blood were discarded. CSF was centrifuged and the supernatant taken. 
When the samples had to be used for the IL-6 bioassay, the whole procedure was performed aseptically. During this procedure the samples were kept on ice. All samples were stored at $-20^{\circ} \mathrm{C}$ until assayed.

\section{Ab Treatment}

Rat mAb to murine rIL-6 (20F3) (16) or to murine interferon- $\gamma$ (IFN $\gamma$ ) (XMGl.2) (17) were prepared as described. Rat mAb to $\beta$-galactosidase (GL113) was used as an isotype control (IgGl) for both anti-cytokine mAbs. Rat IgG purified by chromatography from rat serum (Sigma Chemical Co., St. Louis, MO, U.S.A.) was used as an additional control. mAb and immunoglobulin were diluted to the desired concentration in PBS and injected i.p. at the indicated time points.

\section{IL-6 Bioassay}

IL-6 bioactivity was determined using the hybridoma growth factor (HGF) assay. Briefly, B9 hybridoma cells were added to semilogarithmic sample dilutions in flat-bottom microtiter plates (5000 cells/well). After 4 days of culture, the number of viable cells was estimated by a colorimetric assay (Alamar Blue, Alamar, Inc., Sacramento, CA, U.S.A.). One U/ml of HGF activity was defined as the concentration giving half maximal cell proliferation. A reference preparation of murine rIL-6 was included on each microtiter plate, and the values obtained for the experimental samples were corrected accordingly. The specificity of the assay was confirmed using the 20F3 neutralizing mAb against murine IL-6 (added to each dilution in the assay at a final concentration of $10 \mu \mathrm{g} / \mathrm{ml}$ ).

\section{Antibody Concentration}

Concentration of exogenously administered $\mathrm{mAb}$ in serum and pooled CSF was determined by using a radial immunodiffusion assay, specific for rat IgGl (The Binding Site, San Diego, CA, U.S.A.). Standards were run on each plate, and values obtained for the experimental samples were corrected accordingly.

\section{Histology}

Brain and spinal cord were fixed for $24 \mathrm{hr}$ in $4 \%$ $(\mathrm{w} / \mathrm{v})$ paraformaldehyde in PBS, whereafter they were paraffin-embedded and sectioned. Six-micrometer sections were stained with Giemsa stain.

\section{Statistical Analysis}

The Fisher exact test (one-tailed) and the nonparametric Mann-Whitney $U$ test were used were appropriate (18).

\section{RESULTS}

\section{Actively Induced EAE}

Administration of the $20 \mathrm{~F} 3 \mathrm{mAb}$ to murine IL-6 (2 mg i.p. on Day -1 and Day 7 relative to EAE induction) inhibited the development of actively induced EAE (Fig. 1A and Table 1, Experiment 1). Disease incidence and maximal as well as cumulative disease scores were all significantly reduced when compared with the PBS-treated animals. The isotype control mAb (anti- $\beta$ galactosidase/GL113) did not have this effect. Treatment with anti-IFN $\gamma$ mAb made disease worse. In a second experiment, different doses of anti-IL-6 mAb were given at the same time points (Table 1, Experiment 2). Doses of 2, 1, and $0.5 \mathrm{mg} \mathrm{mAb}$ had comparable effects, although only the disease score of the $2 \mathrm{mg}$ group was statistically different from that of the controls, due to the small sample size of the other groups. Rat IgG, given as an additional control in this experiment, did not have any significant effect. Anti-IL-6 inhibited the development of EAE to the same extent when given either on Day -1 and Day 7, or only on Day - 1, relative to disease induction, whereas a single dose of mAb on Day 7 was completely ineffective (Table 1, Experiment 3). Mortality within $6 \mathrm{hr}$ of the second administration of antibody was seen in 10 of 20 mice given $2 \mathrm{mg}$ anti- $\beta$-galactosidase, 2 of 10 mice given 0.5 $\mathrm{mg}$ anti- $\beta$-galactosidase, 2 of 10 mice given $2 \mathrm{mg}$ rat IgG, 8 of 10 mice given $0.5 \mathrm{mg}$ rat IgG, 1 of 20 mice given $2 \mathrm{mg}$ anti-IL-6, and 1 of 15 mice given $0.5 \mathrm{mg}$ anti-IL-6 (Table 1). This sudden mortality was never observed after a single $A b$ dose.

Brain and spinal cord from animals that received $1 \mathrm{mg}$ mAb to IL- 6 on Day -1 , and that were not diseased at the time of sampling, were compared histopathologically with the CNS from animals that received PBS or anti-IL-6 on Day 8, and that were clinically diseased (three animals per group) (Figs. 2 and 3). Animals that had overt disease (groups treated with PBS or with anti-IL-6 on Day 8) had numerous perivascular inflammatory infiltrates in cerebellum, brain stem, and spinal cord, in contrast to the animals 

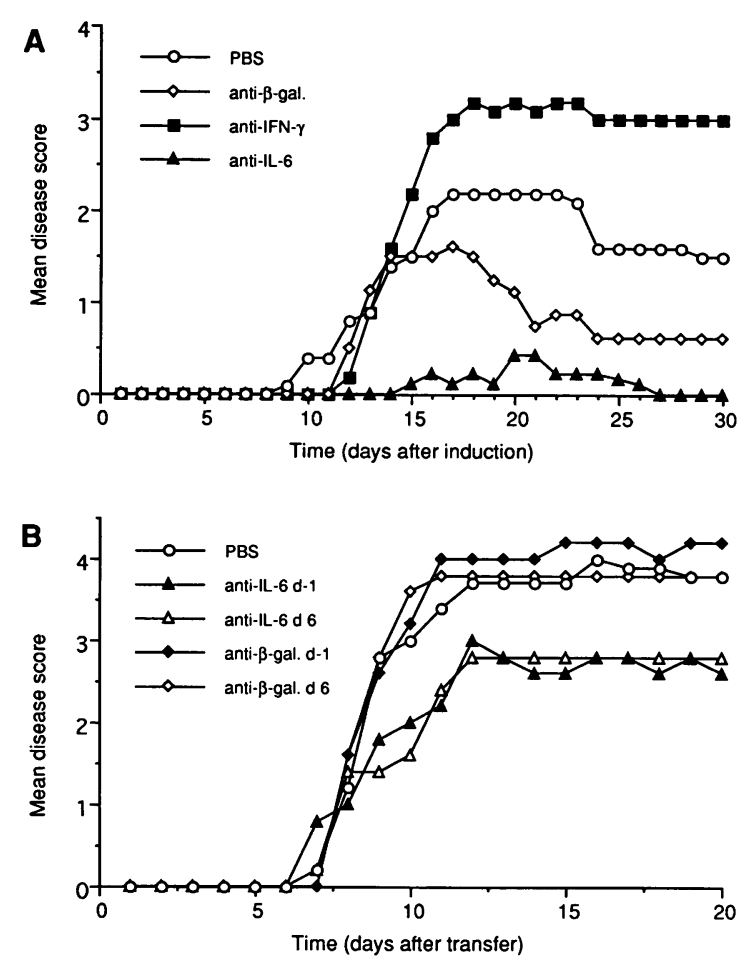

FIG. 1. Effect of Ab to IL-6 on the disease course of EAE

(A) EAE was actively induced by immunizing SJL/J mice s.c. with MSCH in CFA and by giving pertussis toxin i.v. Two milligrams of the indicated mAb or the same volume of PBS was given i.p. on Day -1 and 7 (Table 1, Experiment 1). (B) EAE was adoptively transferred in PLSJLFl mice by i.v. injection of 3.5-5 $\times 10^{6}$ encephalitogenic $\mathrm{T}$ lymphocytes (reactive to $\left.\mathrm{MBP}_{\mathrm{Acl-11}}\right) .0 .5 \mathrm{mg}$ of the anti-IL-6 $\mathrm{Ab}$ or the same volume of PBS was given i.p. on Day -1 or Day 6 (Table 2, Experiment 3). Animals were scored daily as described in Materials and Methods.

treated with anti-IL- 6 on Day -1 that did not have any discernible infiltrates in their CNS.

\section{Adoptively Transferred EAE}

Administration of mAb to IL-6 had similar clinical effects in adoptively transferred EAE. When $0.5 \mathrm{mg}$ mAb was given i.p. on Days $-1,4$, and 8 , relative to transfer of encephalitogenic $\mathrm{T}$ cells, maximal and cumulative disease scores were significantly reduced in one experiment (Table 2, Experiment 1) and mortality and maximal disease scores were significantly reduced in a second independent experiment, in which the disease course was more severe (Table 2, Experiment 2). Even a single dose of the mAb to IL- 6 given on Day 6 (i.e., 1 day before the onset of clinical signs) was effective in significantly reducing the maximal disease score (Fig. 1 and Table 2, experiment 3). The control mAb never had any significant clinical effect in these experiments.

\section{Effect of mAb Administration on IL-6 Levels}

Animals were injected with $1 \mathrm{mg}$ mAb (anti-IL-6 or anti- $\beta$-galactosidase) or PBS on Day -1 or on Day 8 , relative to EAE induction. Animals in which EAE was actively induced were compared with normal noninduced animals. Groups of mice were sacrificed and sampled at one of three time points: $36 \mathrm{hr}$ after EAE induction, at the onset of disease signs, or when such signs had been present for 3 days (all groups were compared relative to disease onset in the PBS-treated EAE group).

Serum IL-6 levels were 5-fold higher in animals $36 \mathrm{hr}$ after EAE-induction $(23 \mathrm{U} / \mathrm{ml})$ than in noninduced animals $(4 \mathrm{U} / \mathrm{ml})$ (Fig. $4 \mathrm{~A})$. Administration of $\mathrm{mAb}$ to IL- 6 increased these levels to up to $67500 \mathrm{U} / \mathrm{ml}$. IL-6 levels were even increased in noninduced animals when given anti-IL-6 $(10 \mathrm{U} / \mathrm{ml})$. IL-6 levels were still increased at the onset of EAE $(58 \mathrm{U} / \mathrm{ml})$ and administration of anti-IL- 6 increased them a further 10 -fold $(501 \mathrm{U} / \mathrm{ml})$.

CSF levels of the cytokine were elevated in animals in which EAE had been induced, whether or not animals were diseased (Fig. 3 and 4B). Levels of IL-6 in animals with EAE were almost 20 times higher after administration of anti-IL-6 $(24000 \mathrm{U} / \mathrm{ml}$, compared with 1380 $\mathrm{U} / \mathrm{ml}$ in animals that received PBS). It should be noted that the mean disease score in the animals immunized to develop EAE, but treated with anti-IL- 6 on Day - 1 , was 0 when CSF was sampled, compared with 2.0 in the PBS group and 1.33 in the animals treated with anti-IL- 6 on Day 8. When anti-IL-6 was given on Day 8, IL-6 levels in serum and CSF were also increased, although serum levels were 3 to 10 times lower than in animals in which anti-IL- 6 was given on Day -1 .

A similar pattern for IL-6 levels, albeit lower, was observed in serum and CSF of animals 3 days after the onset of disease signs. Anti- $\beta$ galactosidase did not significantly affect the IL- 6 levels. Addition of mAb to IL-6 in the bioassay completely blocked all activity in serum 
TABLE 1. Effect of antibodies to IL-6 on the disease course of actively induced EAE

\begin{tabular}{|c|c|c|c|c|c|c|c|}
\hline \multirow[b]{2}{*}{$\begin{array}{l}\text { Experimental } \\
\text { Group }\end{array}$} & \multirow[b]{2}{*}{$\begin{array}{l}\text { Antibody } \\
\text { Dose }\end{array}$} & \multirow{2}{*}{$\begin{array}{l}\text { Time of Antibody } \\
\text { Administration } \\
\text { (days relative } \\
\text { to EAE induction) }\end{array}$} & \multirow[b]{2}{*}{$\begin{array}{c}\text { Disease } \\
\text { Incidence }\end{array}$} & \multirow[b]{2}{*}{ Mortality } & \multirow{2}{*}{$\begin{array}{c}\text { Mean } \\
\text { Maximal } \\
\text { Disease Score } \\
( \pm \text { SEM })\end{array}$} & \multicolumn{2}{|c|}{$\begin{array}{c}\text { Mean } \\
\text { Cumulative } \\
\text { Disease Score }^{a}\end{array}$} \\
\hline & & & & & & $\begin{array}{c}\text { Absolute } \\
\text { ( } \pm \text { SEM) }\end{array}$ & $\%$ \\
\hline \multicolumn{8}{|l|}{ Experiment 1} \\
\hline PBS & - & $-1,7$ & $7 / 10$ & $3 / 10$ & $2.4 \pm 0.67$ & $48.8 \pm 21.4$ & 100 \\
\hline Anti- $\beta$-gal. & $2 \mathrm{mg}$ & $-1,7$ & $5 / 8(10)^{b}$ & $1 / 8$ & $1.8 \pm 0.62$ & $24.8 \pm 18.3$ & 51 \\
\hline Anti-IFN $\gamma$ & $2 \mathrm{mg}$ & $-1,7$ & $9 / 10$ & $6 / 10$ & $3.7 \pm 0.58$ & $80.7 \pm 21.1$ & 165 \\
\hline Anti-IL-6 & $2 \mathrm{mg}$ & $-1,7$ & $2 / 9(10)^{c}$ & $0 / 9$ & $0.6 \pm 0.38^{d}$ & $2.6 \pm 1.8^{d}$ & 5 \\
\hline \multicolumn{8}{|l|}{ Experiment 2} \\
\hline PBS & - & $-1,7$ & $7 / 10$ & $1 / 10$ & $1.9 \pm 0.50$ & $29.2 \pm 11.3$ & 100 \\
\hline \multirow[t]{3}{*}{ Anti- $\beta$-gal. } & $2 \mathrm{mg}$ & $-1,7$ & $0 / 2(10)$ & $0 / 2$ & - & - & - \\
\hline & $1 \mathrm{mg}$ & $-1,7$ & $4 / 5$ & $0 / 5$ & $1.6 \pm 0.40$ & $15.8 \pm 7.2$ & 54 \\
\hline & $0.5 \mathrm{mg}$ & $-1,7$ & $4 / 5$ & $1 / 5$ & $2.2 \pm 0.80$ & $42.4 \pm 30$ & 145 \\
\hline \multirow[t]{3}{*}{ Rat IgG } & $2 \mathrm{mg}$ & $-1,7$ & $5 / 8(10)$ & $0 / 8$ & $1.4 \pm 0.42$ & $18.4 \pm 6.8$ & 63 \\
\hline & $1 \mathrm{mg}$ & $-1,7$ & $3 / 5$ & $1 / 5$ & $1.4 \pm 0.60$ & $23.2 \pm 17.2$ & 80 \\
\hline & $0.5 \mathrm{mg}$ & $-1,7$ & $2 / 5$ & $0 / 5$ & $1.3 \pm 0.75$ & $14.0 \pm 19.8$ & 48 \\
\hline \multirow[t]{3}{*}{ Anti-IL-6 } & $2 \mathrm{mg}$ & $-1,7$ & $2 / 10^{c}$ & $0 / 10$ & $0.5 \pm 0.34^{d}$ & $4.2 \pm 3.7^{d}$ & 14 \\
\hline & $1 \mathrm{mg}$ & $-1,7$ & $1 / 5$ & $0 / 5$ & $0.4 \pm 0.40$ & $6.8 \pm 7.6$ & 23 \\
\hline & $0.5 \mathrm{mg}$ & $-1,7$ & $1 / 5$ & $0 / 5$ & $0.4 \pm 0.40$ & $3.6 \pm 8.0$ & 12 \\
\hline \multicolumn{8}{|l|}{ Experiment 3} \\
\hline PBS & & & $5 / 10$ & $1 / 10$ & $1.3 \pm 0.54$ & $24.3 \pm 16.1$ & 100 \\
\hline \multirow[t]{3}{*}{ Anti- $\beta$-gal. } & $0.5 \mathrm{mg}$ & $-1,7$ & $5 / 7(8)$ & $1 / 7$ & $1.9 \pm 0.63$ & $29.1 \pm 18.3$ & 120 \\
\hline & $0.5 \mathrm{mg}$ & -1 & $4 / 7$ & $4 / 7$ & $2.9 \pm 1.01$ & $79.3 \pm 30.4$ & 326 \\
\hline & $0.5 \mathrm{mg}$ & 7 & $6 / 9$ & $1 / 9$ & $1.7 \pm 0.53$ & $27.3 \pm 15.2$ & 112 \\
\hline \multirow[t]{3}{*}{ Rat IgG } & $0.5 \mathrm{mg}$ & $-1,7$ & $1 / 2(10)$ & $0 / 2$ & 一 & - & - \\
\hline & $0.5 \mathrm{mg}$ & -1 & $4 / 10$ & $1 / 10$ & $1.1 \pm 0.55$ & $15.8 \pm 12.3$ & 65 \\
\hline & $0.5 \mathrm{mg}$ & 7 & $7 / 10$ & $1 / 10$ & $1.8 \pm 0.49$ & $25.4 \pm 12.1$ & 105 \\
\hline \multirow[t]{3}{*}{ Anti-IL-6 } & $0.5 \mathrm{mg}$ & $-1,7$ & $1 / 9(10)$ & $0 / 9$ & $0.2 \pm 0.20$ & $3.1 \pm 3.3$ & 12 \\
\hline & $0.5 \mathrm{mg}$ & -1 & $2 / 10$ & $0 / 10$ & $0.4 \pm 0.27$ & $4.7 \pm 3.5$ & 19 \\
\hline & $0.5 \mathrm{mg}$ & 7 & $6 / 9$ & $1 / 9$ & $2.0 \pm 0.58$ & $27.6 \pm 12.6$ & 114 \\
\hline
\end{tabular}

EAE was actively induced by immunizing SJL mice s.c. with MSCH in CFA and by giving pertussis toxin i.v. Different doses of the mAb, purified rat IgG, or the same volume of PBS were given i.p. as indicated. Animals were scored daily as described in Materials and Methods.

${ }^{a}$ The mean cumulative disease score was calculated by adding the mean daily disease scores from all the animals in a group over the observation period ( 30 days) (expressed as the absolute value \pm SEM and as the percentage of the score of the PBS group). Scores for each group are compared with the scores for the PBS group in that experiment.

${ }^{b}$ The number of animals in each group at the start of the experiment is indicated inthe parentheses; only animals that survived the second $\mathrm{Ab}$ dose (on Day 7) were taken into account for calculations.

${ }^{c} p<0.05$, one-tailed Fisher exact test.

${ }^{d} p<0.05$, Mann-Whitney $U$ test. 

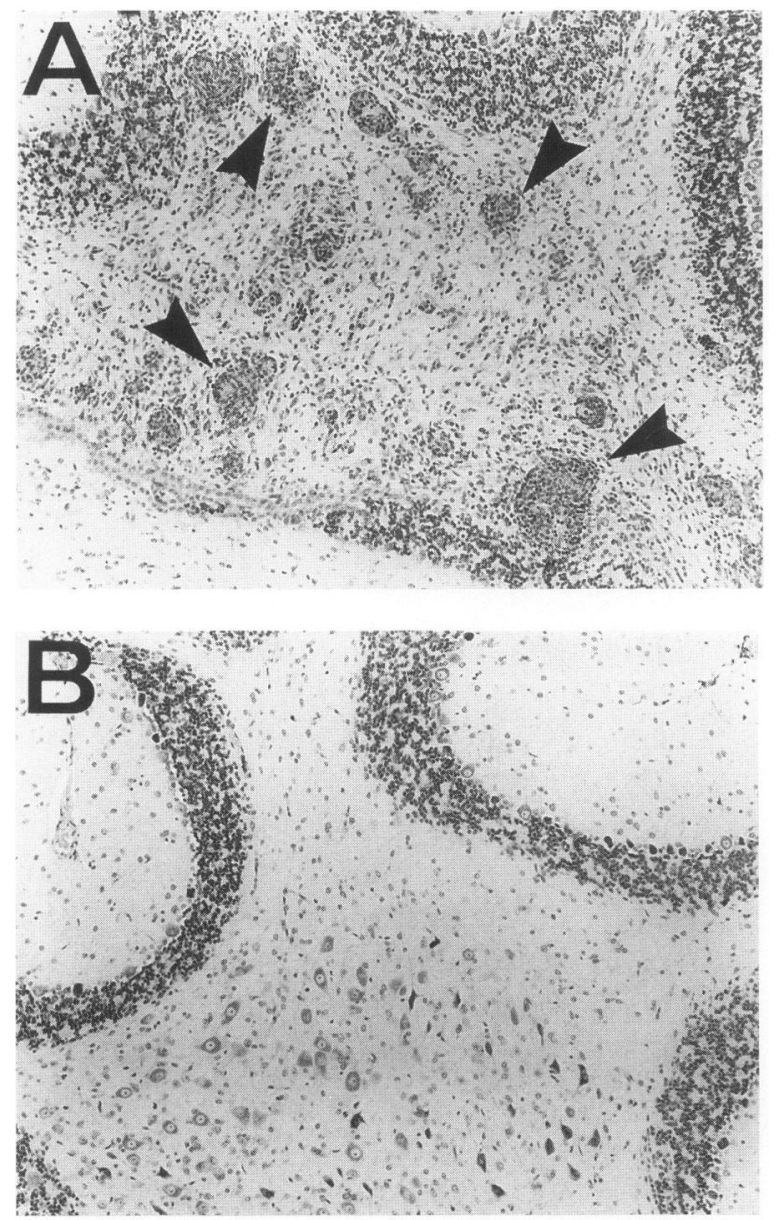

FIG. 2. CNS histopathology of animals treated with anti-IL-6

EAE was acitvely induced by immunizing SJL/J mice s.c. with $\mathrm{MSCH}$ in CFA and by giving pertussis toxin i.v. Animals received $1 \mathrm{mg}$ anti-IL-6 (20F3) mAb or the same volume of PBS i.p. on Day -1 relative to EAE induction, and were sampled when the PBStreated group showed disease signs. (A) Cerebellum of a PBS-treated animal with numerous perivascular inflammatory infiltrates (arrowheads) in the white matter. (B) same area of an anti-IL-6-treated animal, no infiltrate is present. (Giemsa staining, 10×, original magnification).

$(<3 \mathrm{U} / \mathrm{ml})$ and CSF $(<30 \mathrm{U} / \mathrm{ml})$ samples from animals treated with PBS or with anti-IL-6.

\section{Rat IgG1 Levels in Serum and CSF}

Rat IgGl levels were determined on samples from an experiment similar to the one depicted in Fig. 4 (Table 3). All animals were sampled at the time of disease onset in the PBS-treated group. Rat IgGl, administered on Day 8, was detectable and reached comparable levels in the serum, independent of the nature of the mAb (anti-IL-6 or anti- $\beta$-galactosidase) or the clinical condition of the animals (normal or EAE). When administered on Day -1 , serum levels were much lower or fell below detection limit. Rat IgGl was only detectable in the CSF of animals in which EAE was induced, irrespective of the nature of the mAb or the clinical condition of the animals. Levels were just above detection limit $(1 \mu \mathrm{g} / \mathrm{ml})$ when the mAb was given on Day -1 , and 3 times higher when given on Day 8 (approximately $1-2 \%$ of the serum levels).

\section{DISCUSSION}

We administered neutralizing mAb to IL-6 in animals in which EAE was induced to evaluate the role of this pleiotropic cytokine in inflammatory CNS disorders of autoimmune origin. Administration of the $\mathrm{mAb}$ significantly reduced the development of EAE, both in actively induced EAE and in the adoptive transfer model of EAE. A single dose of $\mathrm{mAb}$ was sufficient to cause this effect, and could be given as late as one day before the onset of clinical signs in the adoptively transferred model, although administration of the $\mathrm{mAb}$ around the time of disease induction was most effective in both EAE models. This demonstrates that the mAb is not only acting on the induction phase, but also on the effector phase of the disease (i.e., the inflammatory reaction in the CNS). In actively induced EAE, however, administration on Day 7 or 8 after induction was ineffective, whereas administration on Day -1 was effective (clinical disease onset from Day 9-12). Moreover, the absence of inflammatory infiltrates in the CNS of animals in which EAE was actively induced and that were treated with mAb to IL-6, demonstrates that the protective effect of anti-IL- 6 on the clinical disease was also evident at the histopathological level. AntiIFN $\gamma$ was used as a positive control for anticytokine therapy in EAE, and had the diseaseenhancing effect that has been described previously (19).

Several animals died within $6 \mathrm{hr}$ after the second dose of $\mathrm{Ab}$ (rat anti-IL-6 mAb, rat anti$\beta$-galactosidase $\mathrm{mAb}$, or rat $\mathrm{IgG}$ ). Since the first $\mathrm{Ab}$ dose was given 1 day before immunization with CFA, we conclude that this sudden death was caused by an immunization and anaphylactic reaction to the foreign protein, stimulated by pertussis toxin. We have previously reported on this effect (20). Moreover, animals in which EAE 


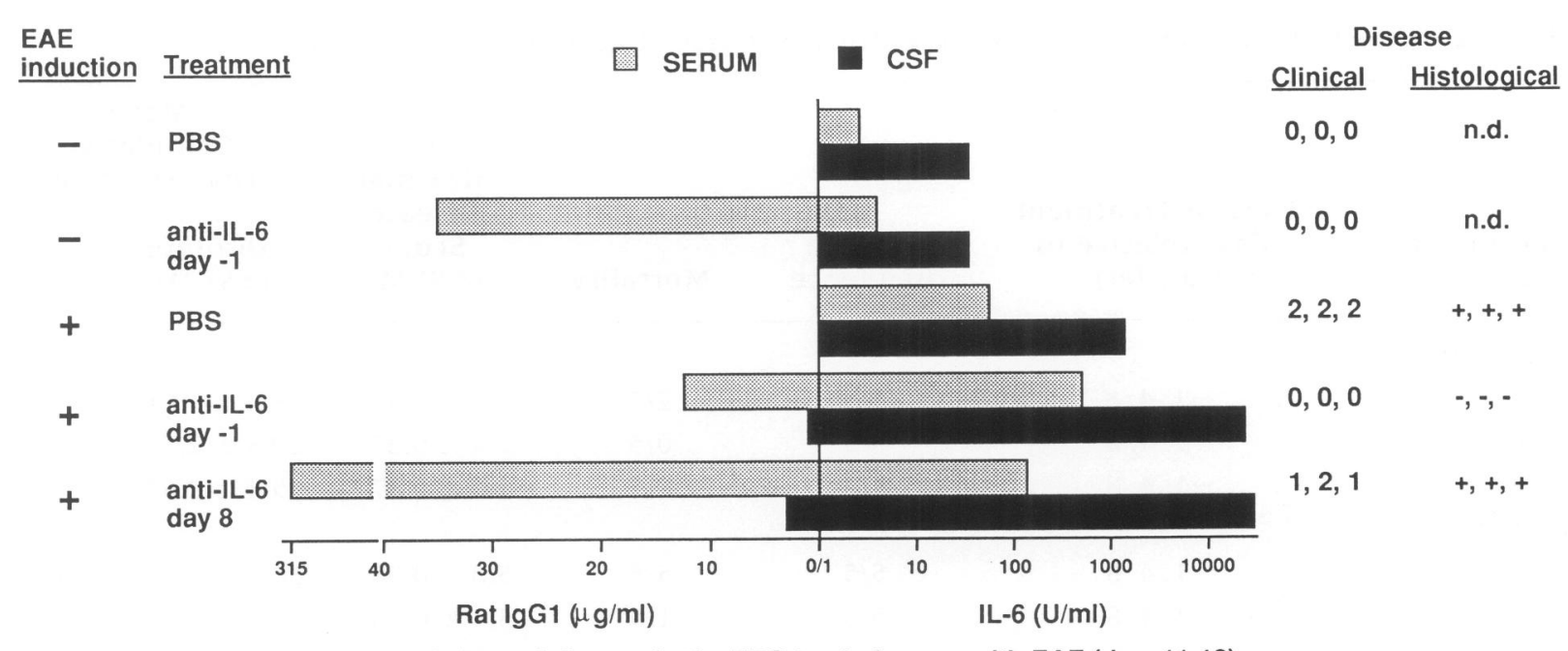

FIG. 3. Relationship between levels of IL-6 and anti-IL-6 Ab in serum and CSF, and EAE expression

IL-6 and anti-IL-6 Ab data are from Fig. 4 and Table 3. The data regarding IL-6 levels and clinical and histological disease are from the same experiment. EAE was scored clinically as described in Materials and Methods. Histology was scored as either + or - , depending on the presence or absence, respectively, of inflammatory infiltrates and demyelination in the CNS. n.d., not determined.

was induced by transfer, where no pertussis toxin is given, and that also received multiple $\mathrm{Ab}$ doses never had this reaction.

Protective effects of anti-IL-6 have been described in several in vivo models of autoimmune or other inflammatory conditions, including autoimmune diabetes (21), systemic lupus erythematosus (22), tumor necrosis factor (TNF) effects (23), endotoxin-induced shock and Shwartzman reaction (24), and Toxoplasma gondii-infection of the CNS $(25,26)$. The conclusion from these studies is that Abs to IL-6 are protective by neutralizing endogenous IL- 6 activity, and hence that IL- 6 has a pro-inflammatory effect in these models. However, there have been reports of increased levels of circulating IL- 6 after administration of mAb to IL- 6 in animals in which IL-6 production was induced $(24,26,27)$ and in a patient with plasma cell leukemia after anti-IL-6 treatment (28). We found increased levels of IL-6 bioactivity in serum of animals treated with mAb to IL-6. In normal animals there was a slight increase in IL-6 levels, but levels were far more increased in animals that already had elevated IL-6 levels 36 $\mathrm{hr}$ after active EAE induction or at the onset of EAE. In addition, we could also demonstrate increased IL- 6 levels in the CSF of animals treated with anti-IL-6, but only in animals in which EAE was induced and that already had elevated IL- 6 levels in their CSF when disease started. IL-6 levels in the CSF were increased to the same extent in animals that received anti-IL- 6 on Day -1 and in animals that received them on Day 8 . Only the former were protected clinically and histopathologically against the development of $\mathrm{EAE}$, indicating that-at least in the actively induced EAE model-anti-IL-6 Abs must be present before Day 8, and that mere elevated IL-6 levels in the CSF are not sufficient to prevent EAE (Fig. 3). Addition of the 20F3 mAb (specific for murine IL-6) to the B9 bioassay completely blocked all IL- 6 bioactivity in sera and CSF from animals in which EAE was induced (anti-IL-6-treated as well as nontreated animals), thereby proving that the biological activity detected could indeed be attributed to IL-6.

Increased IL- 6 levels in the body fluids of anti-IL-6-treated mice may be due to delayed elimination and/or increased production. Complex formation with $\mathrm{Ab}$ may slow down the elimination of IL-6. Neutralization by Ab could reduce the biological availability of IL- 6 and hence reduce the negative feedback that IL-6 may exert over its own production. It has been shown that in vivo administration of anti-IL-6 $\mathrm{Ab}$, in cases where there is elevated IL- 6 production, induces circulating IL-6-Ab complexes that are biologically active in the HGF-assay (27-29). The observation that animals in which EAE had been induced and that received $\mathrm{mAb}$ on Day -1 
TABLE 2. Effect of antibodies to IL-6 on the disease course of adoptive transfer EAE

\begin{tabular}{|c|c|c|c|c|c|c|}
\hline \multirow[b]{2}{*}{$\begin{array}{l}\text { Experimental } \\
\text { Group }\end{array}$} & \multirow{2}{*}{$\begin{array}{c}\text { Time of Treatment } \\
\text { (days relative to } \\
\text { transfer) }\end{array}$} & \multirow[b]{2}{*}{$\begin{array}{c}\text { Disease } \\
\text { Incidence }\end{array}$} & \multirow[b]{2}{*}{ Mortality } & \multirow{2}{*}{$\begin{array}{c}\text { Mean } \\
\text { Maximal } \\
\text { Disease } \\
\text { Score } \\
( \pm \text { SEM })\end{array}$} & \multicolumn{2}{|c|}{$\begin{array}{c}\text { Mean } \\
\text { Cumulative } \\
\text { Disease Score }^{a}\end{array}$} \\
\hline & & & & & $\begin{array}{l}\text { Absolute } \\
\text { ( } \pm \text { SEM) }\end{array}$ & $\%$ \\
\hline \multicolumn{7}{|l|}{ Experiment 1} \\
\hline PBS & $-1,4,8$ & $5 / 5$ & $2 / 5$ & $3.0 \pm 0.84$ & $28.6 \pm 13.1$ & 100 \\
\hline Anti- $\beta$-gal. & $-1,4,8$ & $5 / 5$ & $0 / 5$ & $2.4 \pm 0.25$ & $20.8 \pm 2.7$ & 73 \\
\hline Anti-IL-6 & $-1,4,8$ & $4 / 5$ & $0 / 5$ & $1.2 \pm 0.37^{b}$ & $5.4 \pm 2.6^{b}$ & 19 \\
\hline \multicolumn{7}{|l|}{ Experiment 2} \\
\hline PBS & $-1,4,8$ & $5 / 5$ & $5 / 5$ & $5.0 \pm 0.00$ & $68.6 \pm 0.6$ & 100 \\
\hline Anti-IL-6 & $-1,4,8$ & $5 / 5$ & $1 / 5^{c}$ & $3.4 \pm 0.40^{b}$ & $44.2 \pm 9.4$ & 64 \\
\hline \multicolumn{7}{|l|}{ Experiment 3} \\
\hline PBS & $-1,6$ & $10 / 10$ & $6 / 10$ & $4.2 \pm 0.33$ & $44.8 \pm 4.2$ & 100 \\
\hline \multirow[t]{2}{*}{ Anti- $\beta$-gal. } & -1 & $5 / 5$ & $3 / 5$ & $4.2 \pm 0.49$ & $48.4 \pm 8.1$ & 108 \\
\hline & 6 & $5 / 5$ & $2 / 5$ & $3.8 \pm 0.49$ & $46.0 \pm 6.4$ & 103 \\
\hline \multirow[t]{2}{*}{ Anti-IL-6 } & -1 & $5 / 5$ & $1 / 5$ & $3.2 \pm 0.49$ & $32.4 \pm 10.3$ & 72 \\
\hline & 6 & $5 / 5$ & $1 / 5$ & $2.8 \pm 0.58^{b}$ & $32.2 \pm 5.7$ & 72 \\
\hline
\end{tabular}

EAE was adoptively transferred in PLSJLF1 mice by i.v. injection of 3.5-5 $\times 10^{6}$ encephalitogenic T lymphocytes (reactive to $\left.\mathrm{MBP}_{\mathrm{Acl}-11}\right) .0 .5 \mathrm{mg}$ of the mAb or the same volume of PBS were given i.p. on the indicated time points. Animals were scored daily as described in Materials and Methods.

${ }^{a}$ The mean cumulative disease score was calculated by adding the mean daily disease scores from all the animals in a group over the observation period ( 20 days) (expressed as the absolute value \pm SEM and as the percentage of the score of the PBS group in each experiment). Scores for each group are compared with the scores for the PBS group in that experiment.

${ }^{b} p<0.05$, Mann-Whitney $U$ test.

${ }^{c} p<0.05$, one-tailed Fisher exact test.

had higher serum IL-6 levels on the day of disease onset (11-12 days later) than animals that received the antibody on Day 8 , may reflect accumulation of IL- 6 complexed to Ab over time. It also indicates that these complexes are stable over extended periods of time and that the complexed IL- 6 retains its biological activity. Our results extend the findings in the circulation to other compartments, in this case the CNS, in which there is IL- 6 production. We clearly demonstrated that exogenous Abs can cross the damaged blood-CSF barrier and reach the CSF in EAE. Since there is both widespread meningeal and parenchymatous inflammation in EAE, breakdown of the blood-CSF barrier indicates breakdown of the BBB, and these Abs can be expected to reach the CNS parenchyma as well. IL- 6 levels in CNS tissue are elevated in EAE (11), and we can surmise that anti-IL-6 causes increased IL- 6 levels in the CNS parenchyma as well.

How can we explain the production of IL-6 in the CNS of animals that were protected against the development of EAE and that did not have discernible inflammatory infiltrates in their CNS? Likewise, how could the administered mAb reach the CSF in these animals (Fig. 3)? The most probable explanation is that even in protected animals a limited number of CNS-specific $T$ cells entered the CNS and activated CNS cells to produce IL-6 and other mediators, which in turn could open the BBB to circulating Ab. The antiIL- 6 mAb binds to locally produced IL- 6 and influences its production and biological action (see below), preventing the formation of an inflammatory infiltrate. This model is consistent with the hypothesis that the secondary influx of inflammatory cells is responsible for the formation of the inflammatory infiltrates and the neurological impairment (30). IL-6 production in the CNS has been described in a model of Trypanosoma infection in mice (31) and in a model of mechanical brain injury (32), before any inflam- 


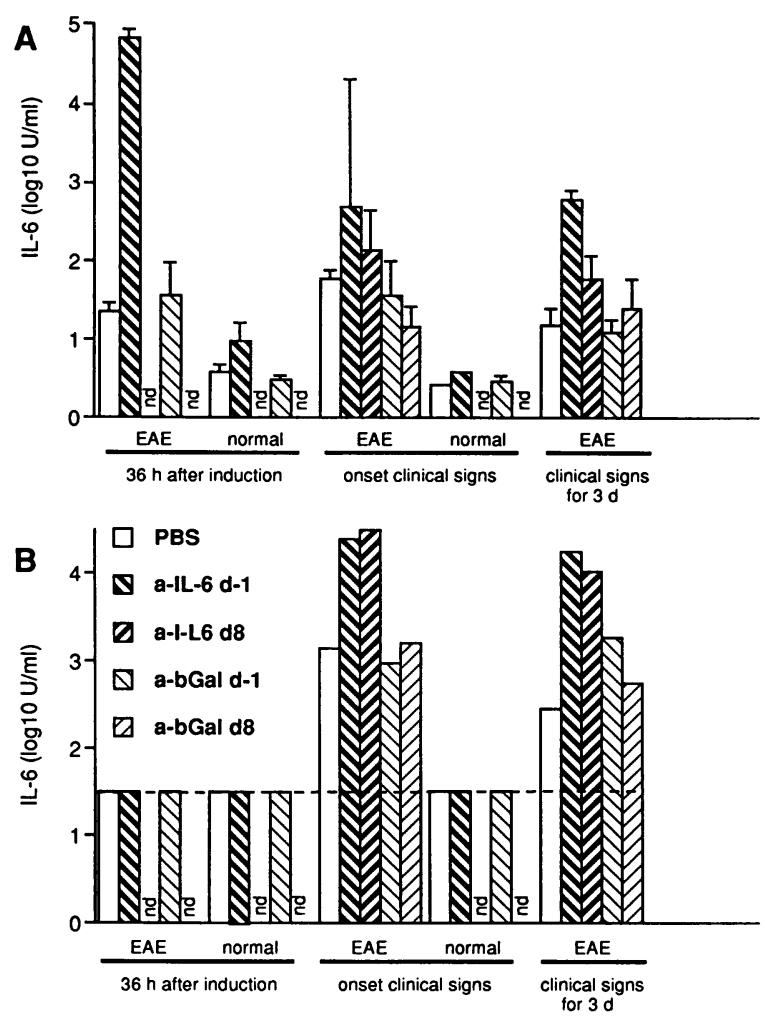

FIG. 4. Effect of neutralizing monoclonal Ab to IL-6 on IL-6 levels in serum and CSF

EAE was acitvely induced by immunizing SJL mice s.c. with $\mathrm{MSCH}$ in CFA and by giving pertussis toxin i.v. Animals received $1 \mathrm{mg}$ of anti-IL-6 (20F3), anti$\beta$-galactosidase (GL113) mAb, or the same volume of PBS i.p. on Day -1 or Day 8 relative to EAE induction. Animals were sampled $36 \mathrm{hr}$ after EAE induction, at disease onset in the PBS-treated group, and 3 days after disease onset in the PBS-treated group. IL-6 levels in serum (A) and CSF (B) were determined by hybridoma growth factor assay. ( $n=3$ /group; values are mean + SEM; nd, not done; detection limit in pooled CSF was $1.5 \log _{10} \mathrm{U} / \mathrm{ml}$ )

matory cells could be detected in the CNS. The detection of IL- 6 transcripts correlated with the onset of astrocyte activation in the Trypanosoma model, and astrocytes are considered to be the source of the cytokine.

In mice treated with mAb to IL- 6 and then challenged with LPS, circulating IL- 6 and Ab are present in equimolar concentrations and are nearly $100 \%$ complexed (29). We did not examine whether the IL-6 was complexed when present in the CSF after mAb treatment, but the molar concentration of mAb could roughly be estimated to exceed that of IL- 6 by a factor of 10 to 30 . IL-6 complexed to anti-IL-6 Ab is known to retain its biological activity in the IL-6-bioas-
TABLE 3. Rat IgGl levels in serum and CSF after administration of rat IgGl monoclonal Ab in animals with EAE

\begin{tabular}{lllc}
\hline & & \multicolumn{2}{c}{ Rat IgGl $(\mu \mathrm{g} / \mathrm{ml})$} \\
\cline { 3 - 4 } $\begin{array}{l}\text { Treatment } \\
\text { Group }\end{array}$ & & \multicolumn{1}{c}{ Serum $^{a}$} & CSF $^{b}$ \\
\hline $\begin{array}{l}\text { Noninduced } \\
\text { PBS }\end{array}$ & & $<1,<1,<1$ & $<1$ \\
anti-IL-6 & $\mathrm{d}-1$ & $33,>40,33$ & $<1$ \\
& $\mathrm{~d} 8$ & $248,254,321(274.3)$ & $<1$ \\
anti- $\beta$-gal. & $\mathrm{d}-1$ & $24,<1,<1$ & $<1$ \\
& $\mathrm{~d} 8$ & $280,242,204(242)$ & $<1$ \\
EAE & & & $<1$ \\
PBS & & $<1,<1,<1$ & 1 \\
anti-IL-6 & $\mathrm{d}-1$ & $1.1,31,5.2(12.4)$ & 2.9 \\
& $\mathrm{~d} 8$ & $243,310,391(314.7)$ & 1 \\
anti- $\beta$-gal. & $\mathrm{d}-1$ & $<1,2,1$ & 3.4 \\
& $\mathrm{~d} 8$ & $216,192,200(202.7)$ & \\
\hline
\end{tabular}

Rat IgGl levels were determined by radial immunodiffusion on serum and CSF samples after administration of $1 \mathrm{mg}$ of anti-IL-6 (20F3), anti- $\beta$-galactosidase (GL113), or PBS on either Day $-1(d-1)$ or Day $8(d 8)$ relative to active EAE induction. Animals were sampled at disease onset in the PBS group (Day 11-12).

${ }^{a}$ Serum levels from individual mice are shown, the mean is given in parentheses where appropriate.

${ }^{b} \mathrm{CSF}$ levels are from pooled CSF ( $n=3$ /group).

say: the affinity of the IL- 6 receptor on the cell line used for the HGF-assay is higher than that of the $A b$, and therefore IL- 6 is still active on the cell line despite its binding to the Ab. This is also reflected in the excess of Ab to IL- 6 necessary for in vitro neutralization of IL-6 activity (29).

It is unknown whether the higher levels of IL- 6 that accumulate as IL-6-Ab complexes, also induce higher in vivo bioactivity of IL-6. Administration of IL- $6-\mathrm{mAb}$ complexes in a molar ratio of 1-2:1 augments some of the biological effects of IL-6 in vivo $(27,33)$. The same observation has been reported for Ab complexes with IL-3, IL-4, and IL-7 (34). It is conceivable however, that different biological effects of IL-6 are influenced to a variable extent by mAb administration, depending on the sensitivity of the cells involved and the kinetics of the effect. Of interest is that transgenic mice with IL- 6 under the regulatory control of the glial fibrillary acidic gene promoter, and in which $\mathrm{IL}-6$ is overexpressed in the CNS, develop a neurological syndrome, associated with 
neuropathologic changes partially reminiscent of EAE (35). The net result of administration of $A b$ to a cytokine is thus dependent on the balance between two opposing effects (i.e., neutralization and accumulation). These findings indicate that the mechanism(s) underlying in vivo effects of antibodies to cytokines are complex. Nevertheless, the protective effect of anti-IL-6 that we observed in EAE might have therapeutic benefit for inflammatory conditions in the CNS, including MS $(5,10,13)$ and certain cases of postinfectious encephalomyelitis $(2-4)$.

\section{ACKNOWLEDGMENTS}

This work was supported by the National Institutes of Health (NS18235) and by contributions from the Mendell Family, Hyman Abadi, the Fahnstock Family, and the Phil N. Allen Trust. DNAX is supported by Shering-Plough. KG was supported by the Belgian National Fund for Scientific Research (NFWO). The authors would like to thank A. Billiau (Leuven, Belgium) for helpful discussion.

\section{REFERENCES}

1. Akira S, Taga T, Kishimoto T: (1993) Interleukin-6 in biology and medicine. $A d v$. Immunol. 54: 1-78.

2. Frei K, Leist TP, Meager A, et al. (1988) Production of B cell stimulatory factor- 2 and interferon $\gamma$ in the central nervous system during viral meningitis and encephalitis. $J$. Exp. Med. 168: 449-453.

3. Houssiau FA, Bukasa K, Sindic CJM, Van Damme J, Van Snick J. (1988) Elevated levels of the $26 \mathrm{~K}$ human hybridoma growth factor (interleukin 6) in cerebrospinal fluid of patients with acute infection of the central nervous system. Clin. Exp. Immunol. 71: $320-$ 323.

4. Frei $\mathrm{K}$, Malipiero UV, Leist TP, Zinkernagel RM, Schwab ME, Fontana A. (1989) On the cellular source and function of interleukin 6 produced in the central nervous system in viral diseases. Eur. J. Immunol. 19: 689-694.

5. Nishimoto N, Yoshizaki K, Eiraku N, et al. (1990) Elevated levels of interleukin-6 in serum and cerebrospinal fluid of HTLV-I associated myelopathy/tropical spastic paraparesis. J. Neurol. Sci. 97: 183-193.

6. Houssiau FA, Devogelaer J-P, Van Damme J,
Nagant de Deuxchaisnes C, Van Snick J. (1988) Interleukin-6 in synovial fluid of patients with rheumatoid arthritis and other inflammatory arthritides. Arthritis Rheum. 31: 784-788.

7. Swaak AJG, Van Rooyen A, Aarden LA. (1989) Interleukin-6 (IL-6) and acute phase proteins in the disease course of patients with systemic lupus erythematosus. Rheumatol. Int. 8: 263-268.

8. Hauser SL, Doolittle TH, Lincoln R, Brown RH, Dinarello CA. (1990) Cytokine accumulations in CSF of multiple sclerosis patients: Frequent detection of interleukin- 1 and tumor necrosis factor but not interleukin-6. Neurology 40: 1735-1739.

9. Maimone D, Gregory S, Arnason BGW, Reder AT. (1991) Cytokine levels in the cerebrospinal fluid and serum of patients with multiple sclerosis. J. Neuroimmunol. 32: 6774.

10. Frei K, Fredrikson S, Fontana A, Link H. (1991) Interleukin-6 is elevated in plasma in multiple sclerosis. J. Neuroimmunol. 31: 147153.

11. Gijbels K, Van Damme J, Proost P, Put W, Carton H, Billiau A. (1990) Interleukin 6 production in the central nervous system during experimental autoimmune encephalomyelitis. Eur. J. Immunol. 20: 233-235.

12. Gijbels K, Van Damme J, Billiau A. (1990) Detection of production of interleukin- 6 , but not of tumor necrosis factor or interferon during experimental autoimmune encephalomyelitis. In: Romagnani S, Abbas AK (ed). Cytokines: Basic Principles and Clinical Applications. Serono Symposia Publications, Raven Press, New York, Vol. 68, p. 67.

13. Maimone D, Annunziata P, Salvadori C, Malamdrini A, Guazzi GC. (1993) IL-6 detection in multiple sclerosis brain. Neurology 43(Suppl 2): Al62.

14. Gijbels K, Billiau A. (1992) Interleukin 6: General biological properties and possible role in the neural and endocrine systems. Adv. Neuroimmunol. 2: 83-97.

15. Brocke S, Gijbels K, Steinman L. (1994) Experimental autoimmune encephalomyelitis in the mouse. In: Cohen IR, Miller AR (eds). Animal Models for Autoimmune Diseases: A Guidebook. Academic Press, Orlando, pp. 1-14.

16. Starnes HF, Pearce MK, Tewari A, Yim JH, Zou J-C, Abrams JS. (1990) Anti-IL-6 monoclonal antibodies protect against lethal Escherichia coli infection and lethal tumor necro- 
sis factor- $\alpha$ challenge in mice. J. Immunol. 145: 4185-4191.

17. Cherwinski H, Schumacher JH, Brown K, Mosmann TR. (1987) Two types of mouse helper T cell clone: III. Further differences in lymphokine synthesis between Thl and Th2 clones revealed by RNA hybridization, functionally monospecific bioassays, and monoclonal antibodies. J. Exp. Med. 166: 12291244.

18. Glantz SA. (1992) Pimer of Biostatistics. 3rd Ed. McGraw-Hill, New York.

19. Billiau A, Heremans H, Vandekerckhove F, et al. (1988) Enhancement of experimental allergic encephalomyelitis in mice by antibodies against IFN- $\gamma$. J. Immunol. 140: 15061510.

20. Black WJ, Munoz JJ, Peacock MG, et al. (1988) ADP-ribosyltransferase activity of pertussis toxin: Immunomodulation by $B$. pertussis. Science 240: 656-659.

21. Campbell IL, Kay TW, Oxbrow L, Harrison LC. (1991) Essential role for interferongamma and interleukin-6 in autoimmune insulin-dependent diabetes in NOD/Wehi mice. J. Clin. Invest. 87: 739-742.

22. Finck BK, Chan B, Wofsy D. (1994). Interleukin 6 promotes murine lupus in NZB/ NZW F1 mice. J. Clin. Invest. 94: 585-591.

23. Libert C, Vink A, Coulie P, et al. (1992) Limited involvement of interleukin-6 in the pathogenesis of lethal septic shock as revealed by the effect of monoclonal antibodies against interleukin-6 or its receptor in various murine models. Eur. J. Immunol. 22: 2625-2630.

24. Heremans H, Dillen C, Put W, Van Damme J, Billiau A. (1992) Protective effect of antiinterleukin (IL)-6 antibody against endotoxin, associated with paradoxically increased IL-6 levels. Eur. J. Immunol. 22: 2395-2401.

25. Hunter CA, Abrams JS, Beaman MH, Remington JS. (1993) Cytokine mRNA in the central nervous system of SCID mice infected with Toxoplasma gondii: Importance of T-cell-independent regulation of resistance to T. gondii. Infect. Immun. 61: 4038-4044.

26. Suzuki Y, Yang Q, Conley FK, Abrams JS, Remington JS. (1994) Antibody against interleukin- 6 reduces inflammation and numbers of cysts in brains of mice with toxoplasmic encephalitis. Infect. Immun. 62: 2773-2778.

27. May LT, Neta R, Moldawer LL, Kenney JS, Patel K, Sehgal PB. (1993) Antibodies chaperone circulating IL-6. Paradoxical effects of anti-IL-6 "neutralizing" antibodies in vivo. J. Immunol. 151: 3225-3236.

28. Lu ZY, Brochier J, Wijdenes J, Brailly H, Bataille R, Klein B. (1992) High amounts of circulating interleukin (IL)- 6 in the form of monomeric immune complexes during antiIL-6 therapy. Towards a new methodology for measuring overall cytokine production in vivo. Eur. J. Immunol. 22: 2819-2824.

29. Martens E, Dillen C, Put W, Heremans H, Van Damme J, Billiau A. (1993) Increased circulating interleukin-6 (IL-6) activity in endotoxin-challenged mice pretreated with anti-IL-6 antibody is due to IL-6 accumulated in antigen-antibody complexes. Eur. J. Immunol. 23: 2026-2029.

30. Steinman L. (1993) Autoimmune disease. Sci. Am. 269: 106-114.

31. Hunter CA, Jennings FW, Kennedy PGE, Murray M. (1992) Astrocyte activation correlates with cytokine production in central nervous system of Trypanosoma brucei bruceiinfected mice. Lab. Invest. 67: 635-642.

32. Yan HQ, Alcaros Banos M, Herregodts $P$, Hooghe R, Hooghe-Peeters EL. (1992) Expression of interleukin (IL)-1b, IL-6 and their respective receptors in the normal rat brain and after injury. Eur. J. Immunol. 22: 2963-2971.

33. Mihara M, Koishihara Y, Fukui H, Yasukawa K, Ohsugi Y. (1991) Murine anti-human IL-6 monoclonal antibody prolongs the halflife in circulating blood and thus prolongs the bioactivity of human IL-6 in mice. Immunology 74: 55-59.

34. Finkelman FD, Madden KB, Morris SC, et al. (1993) Anti-cytokine antibodies as carrier proteins. Prolongation of in vivo effects of exogenous cytokines by injection of cytokine-anti-cytokine antibody complexes. $J$. Immunol. 151: 1235-1244.

35. Campbell IL, Abraham CR, Masliah E, et al. (1993) Neurologic disease induced in transgenic mice by cerebral overexpression of interleukin 6. Proc. Natl. Acad. Sci. U.S.A. 90: 10061-10065. 